\title{
Fontes legais e normativas das políticas socioeducativas no Brasil
}

\section{Legal and regulatory sources of socio-educational policies in Brazil}

\author{
Ronia Lima Barbosa ${ }^{1 *}$, Paulo César de Andrade Marques Santos ${ }^{1}$
}

\begin{abstract}
RESUMO
O presente artigo aborda as principais fontes que embasam as políticas públicas destinadas à aplicação das medidas socioeducativas no contexto brasileiro. O objetivo deste trabalho é trazer, sinteticamente, os meandros que dirigem a aplicação de tais políticas públicas a adolescentes em conflito com a lei, com respeito aos princípios estatutários na seara da infância e juventude. Para a concretude do presente artigo, foram levantados os principais documentos normativos que versam sobre a matéria e que trazem ligação direta ou indireta sobre a temática, desde as obras dispositivas internacionais (Tratados), perpassando pela Constituição Federal Brasileira, até as duas leis principais que regem tais políticas: O Estatuto da Criança e do Adolescente e a Lei do Sistema de Atendimento Socioeducativo (SINASE). Como conclusão, tem-se que, embora os marcos normativos sejam de fundamental importância quanto às diretrizes a ser seguidas pelo aplicador da política, devem ser levados em conta também cada contexto social e individual dos sujeitos destinatários, respeitados os princípios norteadores da doutrina da proteção integral.
\end{abstract}

Palavras-chave: Adolescentes; Fundamentos; Leis; Normas; Socioeducação.

\begin{abstract}
This article addresses the main sources that support public policies for the application of socio-educational measures in the Brazilian context. The objective of this work is to present, in a synthetic way, the intricacies that guide the application of such public policies to adolescents in conflict with the law, with respect to the statutory principles about childhood and youth. For the concreteness of this article, the main normative documents that deal with the subject and that bring direct or indirect connection on the subject were raised, from the international dispositive works (Treaties), permeating the Brazilian Federal Constitution, to the two main laws that govern such policies: The Child and Adolescent Statute and the Socio-Educational Assistance System Law (SINASE). In conclusion, although the normative frameworks are of fundamental importance regarding the guidelines to be followed by the policy applicator, each social and individual context of the recipient subjects must also be taken into account, respecting the guiding principles of the protection integral doctrine.
\end{abstract}

Keywords: Adolescents; Fundamentals; Laws; Norms; Socio-education.

\footnotetext{
${ }^{1}$ Universidade de Pernambuco.

*E-mail: ronia.limab@upe.br
} 


\section{INTRODUÇÃO}

Inicialmente, salienta-se que as fontes legislativas brasileiras são embasadas direta ou indiretamente na Constituição Federal. Assim, portanto, a Carta Magna Brasileira é, por excelência, a principal fonte normativa para as políticas voltadas ao atendimento socioeducativo, seguida das leis ordinárias do País.

Há que se destacar, contudo, que as normas legislativas de um país são, em determinado sentido (direta ou indiretamente), influenciadas por regulações internacionais, tais como Protocolos, Pactos, Convenções e outros. Em assim sendo, o direito da criança e do adolescente também possui ligações junto ao Direito Internacional, tendo em vista as tratativas entre os diversos Estados Soberanos.

Nessa senda, este artigo aborda os principais instrumentos que fundamentam a existência das políticas públicas no âmbito socioeducativo brasileiro, em um viés mais genérico. Para tanto, são apresentadas, em ordem de abrangência e de proximidade, as normativas que exercem função basilar quanto à aplicação das políticas socioeducativas, destinadas a adolescentes em conflito com a lei.

Neste trabalho são analisados tratados internacionais, a Constituição Federal Brasileira e as principais leis ordinárias pátrias, a saber o Estatuto da Criança e do Adolescente (ECA) e a Lei do Sistema Nacional de Atendimento Socioeducativo (SINASE).

Cada instrumento normativo destacado mantém relação normativa entre si e com as situações fáticas que cineticamente constroem a sociedade e, inevitavelmente, as políticas destinadas ao tratamento de adolescentes em conflito com a lei, no percurso socioeducativo. Daí se extrai a importância da presente abordagem.

\section{TRATADOS INTERNACIONAIS}

A partir da Emenda Constitucional n ${ }^{\circ}$ 45, de 30 de dezembro de 2004, o Congresso Nacional incluiu ao art. $5^{\circ}$ da Constituição Federal, um terceiro parágrafo. Segundo esse novo dispositivo constitucional, os Tratados e Convenções Internacionais sobre direitos humanos que forem aprovados em cada Casa do Congresso Nacional, em dois turnos, por 
três quintos dos votos dos respectivos membros, serão equivalentes às emendas constitucionais ${ }^{2}$.

Já com relação aos Tratados e Convenções Internacionais que, embora versem sobre direitos humanos, não foram aprovados conforme o rito acima (uma vez que anteriores à Emenda Constitucional no 45/2004), o Supremo Tribunal Federal (STF), instado a se pronunciar a respeito do tema, estabeleceu que tais normativos não podem ser equiparados às emendas constitucionais, já que foram confirmados em rito diverso do destinado à aprovação daquelas; mas ostentam status supralegal.

Para melhor compreensão do que seria o status supralegal, impende socorrer-nos à classificação hierárquica das normas, feita por Kelsen (1998). Na referida classificação, o jurista cria uma pirâmide, em que no topo está a Constituição Federal e suas emendas, seguida, respectivamente, das leis complementares, leis ordinárias, medidas provisórias e leis delegadas, e resoluções. As normas com status supralegal, portanto, estariam abaixo da Constituição Federal, mas acima das leis complementares e ordinárias.

Assim sendo, a maioria dos Tratados Internacionais de Direito da Criança e do Adolescente têm caráter ou constitucional, ou supralegal, o que fundamenta a conclusão de que estão acima das leis complementares e ordinárias do País, logo, acima do próprio Estatuto da Criança e do Adolescente.

Vale ressaltar, ainda, que a denominação "Tratado Internacional” se refere ao acordo celebrado entre países (pessoas jurídicas de direito público internacional), mediante instrumento escrito, para a produção de efeitos jurídicos na esfera internacional. Segundo o Art. $2^{\circ}$, ponto 1, alínea a, da Convenção de Viena sobre o Direito dos Tratados, de 1969, "Tratado significa um acordo internacional concluído por escrito entre Estados e regido pelo Direito Internacional, quer conste de um instrumento único, quer de dois ou mais instrumentos conexos, qualquer que seja sua denominação específica." (CONVENÇÃO DE VIENA, 1969). “Tratado" é, portanto, gênero, do qual podem ser espécies: Convenções, Pactos, Cartas, Protocolos, Regras, dente outros.

Ademais, para que um Tratado Internacional possua aplicabilidade em determinado Estado, é necessário que este, de forma livre e em pleno exercício de sua soberania, consinta expressamente com seus termos. Significa dizer, por outro lado, que

\footnotetext{
${ }^{2}$ Esse é o mesmo rito destinado às emendas constitucionais, conforme dispõe o art. $60, \S 2^{\circ}$, da Constituição Federal.
} 
os tratados não impõem nenhuma espécie de obrigação àqueles Estados que não manifestarem seu livre consentimento.

Sabe-se que o Direito Internacional detém papel de fundamental relevância na legislação de um país, o que se observa também no que diz respeito às normas da área infanto-juvenil, com grande ênfase nos Tratados de Direitos Humanos que versam sobre direitos atinentes à criança e ao adolescente.

Portanto, após a exposição acima, impera destacar os principais documentos internacionais que fundamentam a garantia dos direitos inerentes à criança e ao adolescente, os quais, em uma ótica geral, embasam o sistema de políticas educacionais destinadas a tais sujeitos.

\section{Carta da Liga sobre as Crianças - Declaração de Genebra de 1924}

Em 1924, foi publicada a Carta da Liga sobre as Crianças, também conhecida como Declaração de Genebra sobre os Direitos da Criança ou Declaração de Genebra, a qual passou a reconhecer a criança como objeto de proteção.

Para Dolinger (2003, p. 81), a Declaração de Genebra é "o primeiro documento de caráter amplo e genérico com relação a criança", já que não focaliza apenas os direitos humanos das crianças, mas contempla a proteção da infância em todos os seus aspectos, prevendo que todas as crianças devem ser auxiliadas, tratadas, reeducadas e colocadas em plenas condições de efetivo e regular desenvolvimento.

A partir da iniciativa privada de uma inglesa chamada Englantine Jebb, foi criada Associação Civil "Save The Children Fund”, voltada à proteção de crianças, que atuou na elaboração do referido documento, com sua publicação em 1924; elencando diversos direitos relativos às crianças, dentre os quais, o de receber ajuda especial em momentos de necessidade, socorro e assistência prioritários, proteção contra exploração, educação voltada à consciência de dever social, dentre outros.

Justamente por isso, a Declaração de Genebra dotou-se de "caráter mais assistencialista do que promotor de direitos" (RAMIRES, 2007, p. 857), em razão do contexto de sua promoção.

É aqui onde, pela primeira vez, em âmbito internacional, há uma especial atenção voltada às pessoas em situação peculiar de desenvolvimento, o que redundou como ponto de partida para outros documentos interpaíses em favor de crianças e adolescentes, a 
exemplo da Declaração dos Direitos da Criança, Regras de Beijing, Regras de Havana, Princípios de Riad, dentre outros.

\section{Declaração dos Direitos da Criança}

Posteriormente, já em novembro de 1959, foi proclamada a Declaração dos Direitos da Criança, e adotada pela Assembleia-Geral da Organização das Nações Unidas (ONU), com fundamento em dez princípios básicos, possui como cerne os direitos básicos de toda criança, dentre os quais se destacam a liberdade, o estudo, a alimentação, a educação e o convívio social.

Em linhas gerais, as Declarações de Direitos desempenham papel importante na formação de novos direitos - tendo em memória também a Declaração Universal dos Direitos Humanos, de 1948, a qual, embora não seja um documento voltado exclusivamente para os direitos da criança e do adolescente, encarta sessão especial destinada a referido público, como a exemplo dos arts. 25 e 26, por meio dos quais reconheceu que a infância tem direito a cuidados e assistência especiais, destinando a todas as crianças, nascidas ou não em relação matrimonial, a mesma proteção especial. Desse modo, na Assembleia-Geral da ONU, a Declaração dos Direitos da Criança, influenciada pela Declaração Universal dos Direitos Humanos, evidenciou um dos fundamentos dos direitos transindividuais.

A Declaração dos Direitos da Criança, aliás, foi responsável por uma mudança de paradigma, na medida em que a criança deixou de ser considerada objeto de proteção (numa ótica de ser passivo, receptor apenas), para figurar, agora, na condição de sujeito de direitos e, em consequência, e em sentido amplo, a própria fase da infância erigiu-se como âmbito coletivo de direitos. Na verdade,

Essa doutrina que a Convenção consolida e que cada Estado Parte aceitou ao ratificar a Convenção, submetendo-se ao compromisso de construir uma ordem legal interna voltada para a efetivação dessa proteção integral, que consubstancie $o$ pleno $e$ integral desenvolvimento de todos os potenciais da criança e seja orientada para a realização do interesse maior dessa mesma criança, de forma a possibilitar o surgimento de um ser humano mais apto a construir e participar de uma sociedade internacional mais justa e equânime. (DUPRET, 2012, p. 29) 
Merecem destaque, ainda nesse contexto, os acréscimos que recebeu a Declaração dos Direitos da Criança: Regras de Beijing, de 1985; Diretrizes de Raid, de 1990, e Regras de Havana, também de 1990. Dupret (2012, p. 30) assim leciona:

A doutrina da proteção integral engloba quatro diplomas internacionais: Convenção das Nações Unidas dos Direitos da Criança, Regras Mínimas das Nações Unidas para a Administração da Justiça de Menores, Regras Mínimas das Nações Unidas para a Proteção dos Jovens Privados de Liberdade, Diretrizes das Nações Unidas para a Prevenção da Delinquência Juvenil. Esse conjunto de disposições internacionais tem força de lei interna para os países signatários, entre eles, o Brasil. (DUPRET, 2012, p. 30)

As Regras de Beijing - também chamadas de Regras Mínimas das Nações Unidas para a Administração da Justiça de Menores - foram adotadas pela Assembleia Geral da ONU, por meio de sua Resolução 40/33, de 29 de novembro de 1985. Trazem recomendações sobre prevenção de delito e tratamento de seu autor, e ainda, por meio do referido Documento, a Justiça da Infância e Juventude passou a ser considerada parte integrante do processo de desenvolvimento nacional de cada país, devendo ser administrada de maneira a contribuir para a manutenção da paz e da ordem social.

Além disso, referido documento destacou com clareza o papel da educação ofertado a crianças e adolescentes institucionalizados, conforme se observa no excerto de seu texto, no tópico 26.6, in verbis:

26.6. Será estimulada a cooperação interministerial e interdepartamental para proporcionar adequada formação educacional ou, se for o caso, profissional ao jovem institucionalizado, para garantir que, ao sair, não esteja em desvantagem no plano da educação. (ONU, 1985)

Além disso, por meio das Regras de Beijing, foi que se enfatizaram as garantias no âmbito das situações de julgamento de crianças e adolescentes que cometeram infrações, então, penais; como por exemplo, a necessidade de oferta de um julgamento justo, imparcial e feito por um juiz especializado. Assim, tais normativos fundaram as primeiras regras do sistema de justiça da infância e juventude, destinadas não apenas às garantias do bem estar de crianças, mas também dos adolescentes.

Já os Princípios Orientadores de Riad - ou Princípios Orientadores das Nações Unidas para a Prevenção da Delinquência Juvenil - apontam diretrizes para que o Estado 
adote políticas de prevenção da delinquência juvenil, elencando em seu bojo, dentre outros dispositivos, os seguintes:

a) A promoção de oportunidades, em especial oportunidades educacionais, para satisfazer as várias necessidades dos jovens e servir como enquadramento de apoio para salvaguardar o desenvolvimento pessoal de todos os jovens, em especial daqueles que se encontram manifestamente em perigo ou em situação de risco social e têm necessidade de cuidados e protecção especiais.

b) A adopção de concepções e de métodos especialmente adaptados à prevenção da delinquência e concretizados nas leis, processos, instituições, instalações e numa rede de serviços destinada a reduzir a motivação, a necessidade e as oportunidades da prática de infracções e a eliminar as condições que dão lugar a tal comportamento. (Parte I, item 5). (ONU, 1990)

Com relação às Regras de Havana - Regras Mínimas das Nações Unidas para a Proteção dos Jovens Privados de Liberdade, estas reconheceram a necessidade de o Estado ofertar tratamento diferenciado ao adolescente em situação de privação de liberdade, justamente em razão de sua alta vulnerabilidade social.

Por meio das Regras de Havana, a ONU estabeleceu que deve ser garantido aos jovens privados de liberdade o direito de poder exercer atividade útil, de fazer parte de programas que visem a manutenção e reforço de sua saúde, bem como que sejam inseridos em políticas educativas; favorecendo, desse modo, seu sentido de responsabilidade social, e, consequentemente, sua reintegração social. Em seus dizeres,

(...) qualquer menor em idade de escolaridade obrigatória tem direito à educação adequada às suas necessidades e capacidades, com vista à preparação da sua reinserção na sociedade. Tal educação deve ser dada, sempre que possível, fora do estabelecimento de detenção em escolas da comunidade e, em qualquer caso, deve ser ministrada por professores qualificados, no quadro de programas integrados no sistema educativo do país, de modo a que os menores possam prosseguir, sem dificuldade, os estudos após a sua libertação. (ONU, 1990)

Referido Documento conceitua privação de liberdade como sendo toda e qualquer forma de prisão, detenção ou colocação de alguém em estabelecimento público ou privado, mediante decisão de autoridade judicial, do qual apenas poderá sair por decisão também judicial.

Convenção sobre os Direitos da Criança 
Outro documento internacional direcionado à área da infância e juventude é a Convenção sobre os Direitos da Criança, a qual foi aprovada pela Assembleia Geral da ONU em 20 de novembro de 1989, por meio da Resolução nº 44, da referida Organização.

A Convenção reconheceu as crianças como sujeitos de direitos, bem como consolidou a doutrina da proteção integral relativamente ao direito infanto-juvenil, sendo crianças e adolescentes, agora, reconhecidos como agentes sociais e titulares de direitos, não meros objetos tutelares.

Segundo Ramires (2007, p. 867), essa Convenção foi “o primeiro código da história a outorgar efeito jurídico e força obrigatória aos direitos específicos da criança". Reside aqui, a diferença básica entre a Declaração e a Convenção dos Direitos da Criança e do Adolescente, uma vez que aquela dota-se de valor simbólico, visto que formada apenas por princípios norteadores; enquanto que esta última detém força coercitiva frente aos Estados que a ratificaram. Segundo Bolieiro e Guerra (2009, p. 15).

\begin{abstract}
A grande diferença entre a Convenção e a Declaração dos Direitos da Criança reside no fato de aquela tornar os Estados que nela são partes juridicamente responsáveis pela concretização dos direitos da criança que a mesma consagra e por todas as ações que adotem em relação às crianças, enquanto a Declaração impunha simplesmente obrigações de natureza moral que se reconduziam a princípios de conduta para as nações. (BOLIEIRO; GUERRA, 2009, p. 15)
\end{abstract}

Esse documento se tornou, no tocante à matéria, o mais representativo, sobretudo por ser o tratado internacional sobre direitos humanos com maior número de Estados aderentes. No âmbito brasileiro, a Convenção foi ratificada pelo Governo Federal em 26 de novembro de 1990, e promulgada pelo Decreto Executivo no 99.710, de 21 de novembro de 1990.

A Convenção sobre os Direitos das Crianças, composta por 54 artigos, abarcou a todas as pessoas menores de dezoito anos, salvo no caso em que a legislação pátria soberana do Estado-membro concebesse o alcance da maioridade antes dos dezoito anos.

Dentre os direitos incluídos no referido documento, encontra-se o direito à educação, e, em consequência, a obrigação do Estado em garantir a todas as pessoas menores de dezoito anos a educação em geral, devendo ser a primária, garantida de forma compulsória e gratuita. 


\section{CONSTITUIÇÃO FEDERAL BRASILEIRA DE 1988}

Ao falar da Constituição Federal, impossível não trazer à mente um dos seus princípios basilares, qual seja, o da dignidade da pessoa humana, estampado logo no art. $1^{\circ}$, III, da Carta Magna. É exatamente aqui que se inicia a proteção constitucional à infância e à juventude. O olhar do Estado a tais sujeitos reside, também, nesse ponto específico da Constituição.

A partir de então, toda a legislação voltada à matéria, quer seja da seara infracional, quer seja da seara protetiva, deve levar em consideração, como princípio a se seguir e perseguir a dignidade da pessoa humana, corolário à própria condição peculiar de pessoa em desenvolvimento. Segundo Veronese (2006, p. 09/10),

Quando a legislação pátria recepcionou a Doutrina da Proteção Integral fez uma opção que implicaria num projeto político-social para o país, pois ao contemplar a criança e o adolescente como sujeitos que possuem características próprias ante o processo de desenvolvimento em que se encontram, obrigou as políticas públicas voltadas para esta área a uma ação conjunta com a família, com a sociedade e o Estado. (VERONESE, 2006, p. 09/10)

Assim, tendo a Constituição Federal alicerce nos documentos internacionais de garantia dos direitos do Homem e também da criança e do adolescente, percebe-se cristalina a disposição do paradigma da absoluta prioridade que deve ser destinada a tais sujeitos. Segundo Saraiva (2002, p. 18), essa nova forma de o Estado vê-los

(...) trouxe a estes agentes da condição de objeto do processo para o status de sujeitos do processo, consequentemente detentores de direitos e obrigações próprios do exercício da cidadania plena, observada sua condição peculiar de pessoa em desenvolvimento, cumprindo um dos princípios fundamentais da Constituição Federal Brasileira, que estabelece no seu art. $1 .^{\circ}$, inciso III, como fundamento da República, a dignidade da pessoa humana. (SARAIVA, 2002, p. 18)

Com efeito, a Carta Constitucional de 1988 é, por muitos, cunhada de Constituição Cidadã. Não por acaso, ela voltou seu olhar à criança e ao adolescente, garantindo-lhes os direitos como absoluta prioridade, conforme se depreende do seu art. 227: 
Art. 227. É dever da família, da sociedade e do Estado assegurar à criança, ao adolescente e ao jovem, com absoluta prioridade, o direito à vida, à saúde, à alimentação, à educação, ao lazer, à profissionalização, à cultura, à dignidade, ao respeito, à liberdade e à convivência familiar e comunitária, além de colocá-los a salvo de toda forma de negligência, discriminação, exploração, violência, crueldade e opressão. (BRASIL, 1988)

Como se percebe, a norma em tela cinge-se de determinação destinada à família, ao Estado e à sociedade em geral, conferindo a tais agentes sociais a competência paralela e concorrente quanto à garantia dos direitos inerentes à infância e juventude, com o fito precípuo de ampliar o alcance da proteção destinada a tais sujeitos.

Referido dispositivo, aliás, faz parte do título VII da Constituição Federal, que aborda, além de direitos da família e do idoso, direitos destinados à infância e à juventude, numa conjuntura com o contexto cinético da sociedade da época, que atravessava transformações urgentes por tutelas legais específicas para cada grupo social mencionado, fato não concebido nas constituições anteriores.

Claro que as constituições pregressas não podiam prever o que o Texto de 1988 previu, pois, no passado, os problemas eram diferentes, os costumes eram outros, o modus vivendi se exteriorizava de forma totalmente distinta da atual. [...] Nesse contexto, o constituinte brasileiro de 1988 não olvidou os contornos modernos da mutável concepção de família. A problemática da marginalização infantil, outrora situada a latere do processo de reintegração social, também foi destacada. $\mathrm{O}$ mesmo se diga quanto às questões relacionadas à adolescência, marcantes nesse crepúsculo de século, sobretudo diante da violência e da exploração sexual dos jovens. (BULLOS, 2008, p. 1132)

É nesse ponto, consequentemente, que se implanta um olhar percuciente às pessoas em peculiar condição de desenvolvimento, com enfoque em uma nova doutrina, a da proteção integral. Para Liberati (2003), a proteção é integral não apenas por força do mandamento constitucional, mas, sobretudo, por se contrapor às doutrinas anteriores, dotadas de vieses repressivista, menorista ou unicamente tutelar.

Ainda segundo o autor, "por absoluta prioridade, devemos entender que a criança e o adolescente deverão estar em primeiro lugar na escala de preocupação dos governantes" (LIBERATI, 2003, p. 30). Com efeito, em diversos outros dispositivos, a Constituição Federal enfatiza sua defesa pela proteção da criança e do adolescente, como 
a exemplo do art. $6^{\circ}$ constitucional, que proclama a proteção à infância como um direito social.

Antes, porém, de ser promulgada a atual Constituição, crianças e adolescentes brasileiros eram referenciados como menores e viviam à margem da condição de sujeitos, e o Poder Judiciário apenas poderia ser acionado quando da ocorrência de situações de rua, cometimento de ato infracional (que à época eram cunhados como atos de delinquência), ou em casos de patologias. Ou seja, o acesso de crianças e adolescentes à justiça era limitado por aquelas circunstâncias previamente descritas no Código de Menores, sendo as demais situações alheias à proteção jurídica.

Nessa esfera, não havia determinação legal que assegurasse especificamente ao público infanto juvenil a garantia de direitos fundamentais; o que era destinado apenas à família, a qual, por sua vez, detinha todos os direitos e obrigações quanto à tutela das crianças e adolescentes, à exceção daqueles falados acima (em que o Estado detinha poder de ingerência familiar). Em consequência, o Estado e a sociedade mantinham-se alheios a qualquer dever de garantia.

Como já dito em tópico anterior, a Declaração Universal dos Direitos da Criança foi um baluarte para a mudança de paradigma quanto ao tratamento destinado aos mais jovens. Com o surgimento da doutrina da proteção integral, crianças e adolescentes deixam de ser objetos de direitos e passam a ser sujeitos de direitos e obrigações próprios do exercício pleno da cidadania, com privilegiado acesso ao sistema de Justiça, e a educação sendo-lhe um direito subjetivo. Em seu art. 208, a Constituição Federal proclama que

Art. 208. O dever do Estado com a educação será efetivado mediante a garantia de: I - Educação Básica obrigatória e gratuita dos 4 (quatro) aos 17 (dezessete) anos de idade, assegurada inclusive sua oferta gratuita para todos os que a ela não tiveram acesso na idade própria. (BRASIL, 1988)

Em consequência, a família deixa de ser detentora exclusiva do dever de proteção, o que se estendeu para o Estado e a Sociedade em geral, passando, também estes a serem, em igualdade de obrigações, responsáveis pela tutela dos direitos da criança e do adolescente, conforme se observa do já mencionado art. 227. 
Percebe-se, pois, que proteger de forma integral é dar atenção diferenciada à criança, rompendo com a igualdade puramente formal para estabelecer um sistema normativo que se incline na busca pela igualdade material, por meio de um tratamento desigual, privilegiado, à criança assegurando-lhes a satisfação de suas necessidades básicas, tendo em vista sua especial condição de pessoa em desenvolvimento. (DUPRET, 2012, p. 29)

A partir da doutrina da proteção integral, portanto, é que se estabelece que as formas de responsabilização de crianças e adolescentes devem ser diferenciadas das medidas de responsabilização destinadas a pessoas maiores de dezoito anos, sendo que, à criança e ao adolescente devem destinar-se as ações do Poder Público e demais agentes sociais, pautadas na educação social daqueles.

\section{LEGISLAÇÃO BRASILEIRA}

Com toda a base oriunda das tratativas internacionais e do mandamento constitucional, a legislação brasileira toma fôlego para disciplinar as políticas que devem ser aplicadas ao contexto socioeducativo. Socioeducativo, nesse caso, porque tem em vista que a responsabilização das pessoas em condição peculiar de desenvolvimento deve ter como foco a educação social.

\section{Estatuto da Criança e do Adolescente - ECA}

Com alicerce nos ordenamentos já dantes expostos, a Lei nº 8.069/1990 é publicada no dia 13 de julho de 1990, chamada de Estatuto da Criança e do Adolescente - ECA. Já em seu artigo primeiro, o ECA aponta como baluarte a doutrina da proteção integral, já vigente no ordenamento brasileiro desde a Constituição Federal de 1988: "Esta Lei dispõe sobre a proteção integral à criança e ao adolescente".

Não há como negar que, a partir desse momento, a proteção integral destinada a crianças e adolescentes deixa de ser apenas um princípio e passa a ser, também, um instituto quase material, palpável, com lei própria sobre sua aplicação.

Para assumir tal posição, o legislador pautou-se na interpretação sistemática dos dispositivos constitucionais e estes, por sua vez, originaram-se a partir de inspirações de 
normas internacionais sobre direitos humanos, tais como a Declaração Universal dos Direitos Humanos, a Convenção Sobre os Direitos da Criança, entre outros.

Diferentemente do que ocorre com a maioria das leis brasileiras, o ECA, em sua elaboração não contou apenas com um grupo selecionado de juristas. Ao revés, resultou da reflexão, participação e diálogo de diversos segmentos sociais, a exemplo de grupos organizados da sociedade, e inúmeros profissionais das áreas de saúde, educação, assistência social, instituições de atendimento de crianças e adolescentes, dentre outros; elevando a consideração da realidade social, e objetivando ampliar o alcance da proteção à criança e ao adolescente.

Tais ações, seus objetivos e resultados, constituem-se, segundo Rossato, Lépore e Cunha (2012, p. 74), de um “"metaprincípio' da prioridade absoluta dos direitos da criança e do adolescente", sendo considerado como a base do ECA. Continuam os autores aduzindo que, a partir de referido instituto:

Pretende-se, pois, que a família se responsabilize pela manutenção da integridade física e psíquica, a sociedade pela convivência coletiva harmônica, e o Estado pelo constante incentivo à criação de políticas públicas. Trata-se de uma responsabilidade que, para ser realizada, necessita de uma integração, de um conjunto devidamente articulado de políticas públicas. Essa competência difusa, que responsabiliza uma diversidade de agentes pela promoção da política de atendimento da criança e do adolescente, tem por objetivo ampliar o próprio alcance da proteção dos direitos infanto-juvenis. (ROSSATO; LÉPORE; CUNHA, 2012, p. 74)

É, portanto, na própria ideia de proteção dos direitos humanos, da prioridade absoluta e da proteção integral da criança e do adolescente, que o formato adotado para tratar de sua responsabilização em face do cometimento de condutas infracionais é diverso daquele destinado a pessoas maiores de dezoito anos.

Com efeito, o principal elemento diferenciador é a educação. Aliás, o próprio ECA institui, em seu art. 53, que "a criança e o adolescente têm direito à educação, visando ao pleno desenvolvimento de sua pessoa, preparo para o exercício da cidadania e qualificação para o trabalho [...]" (BRASIL, 1990).

Nesse viés, ao praticar um ato infracional, o adolescente é sancionado com medida socioeducativa, cujo fim primeiro é sua ressocialização, peça basilar da perpetuação do ser humano como um todo, principalmente no tocante aos princípios de honestidade e respeito mútuos, evitando-se que este continue a não enxergar os limites que a sociedade 
impõe sobre as pessoas e, ainda, a não perceber que suas condutas são tidas como infração "penal".

Especificamente nesse ponto, é que são instituídas as formatações para a responsabilização do adolescente, em caráter socioeducativo. Aliás, todo o teor normativo do ECA referente à pratica do ato infracional pode ser dividido em normas de Direito Material e normas de Direito Processual, as quais tanto definem a conduta infracional, quanto prescrevem os procedimentos que devem ser adotados.

As medidas socioeducativas são aplicadas, após o devido processo legal, aos adolescentes (pessoas de 12 a 18 anos incompletos) que cometeram ato infracional, e estão elencadas no art. 112, do ECA, em rol taxativo e ordenadas, respectivamente, conforme seu grau de rigidez.

São elas: advertência, obrigação de reparar o dano, prestação de serviço à comunidade, liberdade assistida, inserção em regime de semiliberdade, internação em estabelecimento educacional ou qualquer uma das medidas protetivas previstas no art. 101, I a VI, do mesmo diploma legal.

De todas as medidas, conforme se observa, a medida de internação é a mais rígida. Ainda assim, o legislador estabeleceu que esta deve ocorrer em estabelecimento educacional (e não em estabelecimento prisional), e ainda determinou, no art. 123, parágrafo único, que "durante o período de internação, inclusive provisória, serão obrigatórias atividades pedagógicas" (BRASIL, 1990); o que ratifica seu caráter pedagógico.

Em consequência, a ideia de educação é também central nesse contexto, o que realça o dever estatal de garantia do ensino por parte do Estado, que, passa a ser, nesse conjunto, o tutor do adolescente que se encontra em situação de internação. A teor dessa discussão, o Estatuto destina o seu Capítulo IV, que engloba os artigos 53 a 59, para falar “do direito à educação, à cultura, ao esporte e ao lazer", sendo que destes, apenas o art. 59 não trata especificamente do direito à educação.

\section{Lei do Sistema Nacional de Atendimento Socioeducativo - SINASE}

Em 2006, passou a ter vigor no Brasil o Sistema Nacional de Atendimento Socioeducativo (SINASE). Regido pela Resolução no 119 do Conselho Nacional dos Direitos da Criança e do Adolescente (CONANDA), trata-se de uma política pública voltada aos adolescentes em conflito com a lei e em cumprimento de medidas 
socioeducativas, cujo cerne apresenta um conjunto de critérios e normas nas esferas estaduais/distrital e municipais de governo.

Posteriormente, foi publicada a Lei $\mathrm{n}^{\circ}$ 12.594, de 18 de janeiro de 2012, (Lei do Sistema Nacional de Atendimento Socioeducativo - SINASE), pela qual se regulamentou a execução das medidas socioeducativas destinadas a adolescentes que cometem ato infracional. Essa Lei traz as formatações gerais e específicas atinentes à matéria, desde os conceitos relativos ao contexto da execução de medidas socioeducativas, perpassando pelo estabelecimento das competências das esferas de governo e pelas normativas gerais destinadas às unidades, aos gestores, às políticas e programas no âmbito da socioeducação, dentre outros. Outrossim, o SINASE destina-se à organização do atendimento a adolescentes em cumprimento de medidas socioeducativas. Consoante Saraiva (2010, p. 134), trata-se de um

Conjunto ordenado de princípios, regras e critérios que envolvem a execução de medidas socioeducativas incluindo-se nele, por adesão, os sistemas estaduais, distrital e municipais, bem como todos os planos, políticas e programas específicos de atendimento a adolescente em conflito com a lei. (SARAIVA, 2010, p. 134)

Vale dizer, a Lei do SINASE também orienta no sentido de obrigar a promoção da educação nas unidades de atendimento socioeducativo. Assim, estipulou, em seu art. 82, a obrigatoriedade de todos os adolescentes em cumprimento de medida socioeducativa serem inseridos na rede pública de ensino, em qualquer nível de instrução, faixa etária ou fase do período letivo, no prazo de um ano, contado a partir de sua publicação.

Nesse trilhar, a Lei do SINASE (assim como a determinação do ECA) impõe que o cumprimento das medidas socioeducativas de internação e de semiliberdade ocorram em estabelecimento educacional, com infraestrutura adequada, e de acordo com as normas técnicas vigentes. Nesse caso, porém, com "estabelecimento educacional", a Lei se refere à própria unidade de internação ou semiliberdade, ou seja, a estrutura física onde são aplicadas as medidas, e não à mera existência de uma escola dentro da unidade.

Sendo uma política pública, ou, conforme Saraiva (2002), “um conjunto de princípios, regras e critérios", o SINASE se constitui de uma série de serviços, programas, projetos e ações em rede. Assim, o SINASE compõe-se de articulação entre os sistemas de Justiça, de Ensino, de Segurança Pública, de Saúde, de Assistência Social, todos 
integrantes do sistema geral de garantia de direitos, e com vistas a levar o adolescente em cumprimento de medida socioeducativa ao seu desiderato, qual seja, a reintegração social.

Trata-se, portanto, de uma política pública, cuja implementação tem como fim precípuo a aplicação das medidas socioeducativas pautadas em todos os princípios atinentes aos direitos da pessoa humana, com fundamento nos Tratados Internacionais sobre Direitos Humanos, aos quais o Brasil ratificou (sobretudo aqueles que tratam dos direitos da infância e juventude); na Constituição Federal, e no Estatuto da Criança e do Adolescente.

\section{CONSIDERAÇÕES FINAIS}

Este artigo se debruçou em elencar os principais institutos regentes e aplicáveis à socioeducação no contexto brasileiro, abordando-os em ordem cronológica de entrada em vigor, e de acordo com o nível de abrangência geografia e hierárquica.

Com efeito, deve-se ressaltar que, embora as políticas públicas aqui faladas estejam alicerçadas nas normativas legais existentes, não se pode desconsiderar a importância da contextualização de cada medida aplicada, de cada adolescente atendido.

Tais dispositivos existem, na verdade, para guiar o aplicador da política socioeducativa, de modo a evitar que sejam cometidos atos violadores dos direitos já previamente garantidos pelo adolescente, enquanto pessoa em peculiar condição de desenvolvimento.

Tem-se, assim, a importância das Normas (em sentido amplo - aqui englobando os instrumentos internacionais, a própria Constituição Federal e as leis ordinárias) para a correta observância dos princípios garantistas e protetivos a serem observados quando da aplicação da medida socioeducativa.

\section{REFERÊNCIAS}

BOLIEIRO, Helena; GUERRA, Paulo. A criança e a família: uma questão de direito(s). Coimbra: Coimbra, 2009.

BRASIL. Constituição da República Federativa. Promulgada em 5 de outubro de 1988. Disponível em 
http://www.planalto.gov.br/ccivil_03/constituicao/constituicaocompilado.htm Acesso em 30/10/2018

BRASIL. Estatuto da Criança e do Adolescente. Lei no 8.069 de 13 de julho de 1990. Vade mecum. São Paulo: Saraiva, 2015.

BRASIL. Lei do Sistema Nacional de Atendimento Socioeducativo - SINASE. Lei $\mathrm{n}^{\mathrm{o}} 12.594$, de 18 de janeiro de 2012. Disponível em

http://www.planalto.gov.br/ccivil_03/_ato2011-2014/2012/lei/112594.htm Acesso em 28/10/2019.

BULLOS, Uadi Lammêgo. Curso de direito constitucional. 2. Ed. São Paulo: Saraiva, 2008.

CONVENÇÃO de Viena sobre o Direito dos Tratados. VIENNA Convention on the Law of Treaties. 22 maio 1969. Disponível em:

http:www.un.org/law/ilc/texts/treaties.htm. Acesso em 15/04/2018.

DOLINGER, Jacob. A criança no direito internacional. Rio de Janeiro: Renovar, 2003.

DUPRET, Cristiane. Curso de Direito da Criança e do Adolescente. - 2. Ed. - Belo Horizonte: lus, 2012.

KELSEN, Hans. Teoria pura do direito / Hans Kelsen, 1881-1973; - tradução João Baptista Machado. $6^{a}$ ed. - São Paulo: Martins Fontes, 1998.

LIBERATI, Wilson Donizeti. Comentários ao estatuto da criança e do adolescente. São Paulo: Malheiros, 2003.

ONU - Organização das Nações Unidas. Regras Mínimas das Nações Unidas para a Administração da Justiça de Jovens. Adotadas pela Assembleia Geral das Nações Unidas na sua Resolução 40/33, de 29 de novembro de 1985. Disponível em https://gddc.ministeriopublico.pt/sites/default/files/regras_minimas_beijing.pdf Acesso em $03 / 02 / 2021$

ONU - Organização das Nações Unidas. Princípios Orientadores das Nações Unidas para a Prevenção da Delinquência Juvenil. Assembleia Geral das Nações Unidas Doc. No A/CONF. 157/24, de 14 de dezembro de 1990. Disponível em http://www.direitoshumanos.usp.br/index.php/Crian\%C3\% A7a/principios-das-nacoesunidas-para-a-prevencao-da-delinqueencia-juvenil-principios-orientadores-de-riad.html Acesso em 04/02/2021.

RAMIRES, Rosana Laura de Castro Farias. Reflexões sobre a proteção dos direitos humanos das crianças. In: PIOVESAN, Flávia, IKAWA, Daniela (Coord.). Direitos humanos: fundamentos, proteção e implementação. v. 2. Curitiba: Juruá, 2007.

ROSSATO, Luciano Alves; LÉPORE, Paulo Eduardo; CUNHA, Rogério Sanches. Estatuto da Criança e do Adolescente comentado: Lei 8.069/1990: artigo por artigo. 4. ed. Ver., atual. e ampl. - São Paulo: Editora Revista dos Tribunais, 2012. 
SARAIVA, João Batista da Costa. Direito penal juvenil: adolescente e ato infracional. Garantias processuais e medidas socioeducativas. $2^{\mathrm{a}}$ Ed, Porto Alegre. Livraria do Advogado, 2002.

SARAIVA, João Batista Costa. Compêndio de direito penal juvenil: adolescente e ato infracional. 4. ed. rev. atual. Incluindo o Projeto do SINASE e Lei n 12.010/2009Porto Alegre: Livraria do Advogado Editora, 2010.

VERONESE, Josiane Rose Petry. Direito da Criança e do Adolescente. 5 v. Florianópolis: OAB/SC, 2006.

Recebido em: 01/11/2021

Aprovado em: 25/11/2021

Publicado em: 02/11/2021 